\title{
Comparative Analysis of Academic Performance According to Substance Use Status of Students of Ambo University, College of Medicine and Health Sciences, Ethiopia
}

\author{
Gerbaba Guta \\ Department of Public Health, Ambo University, College of Medicine and Health Sciences
}

\begin{abstract}
Background. Studies have shown that students use substances for different reasons including: to enhance their academic performance, for stimulant effect, to overcome stress and to be integrated with substance using community (groups). The aim of this study was to test whether the academic performance of substance user is different from that of non-substance user students.

Methods. Cross sectional study design was employed to analyze the academic performance of 133 (60 substance users and 73 non-users) undergraduate graduates of 2017 at Ambo University, College of medicine and health sciences. Independent t-test was performed to compare substance user students' academic performance with that of non-substance user students.

Results. Out of the study participants, 60(45.1\%) have used at least one of the substances (alcohol, khat or cigarette). The most commonly used substance was alcohol. The average cumulative grade point (CGPA) of substance users was $3.20(\mathrm{SD}=0.42)$ while it was $3.16(\mathrm{SD}=0.45)$ for non-substance users. CGPA mean difference between substance user and non-substance students was not statistically significant (Mean difference $=0.04 ; 95 \%$ CI: -0.11 to $0.19 ; \mathrm{t}=0.549, \mathrm{df}=131, \mathrm{p}$-value $=0.584)$.

Conclusion. The findings suggest that substance users and non-substance users students' academic performance was similar. The hypothesis test result was against substance user students' perception of substance use to enhance academic performance. Therefore, substance user students were compromised their health and social functioning for no more better educational attainment than non-substance user students.
\end{abstract}

Keywords: Academic performance, comparative analysis, independent t-test, substance use.

DOI: $10.7176 / \mathrm{JHMN} / 67-01$

Publication date:October $31^{\text {st }} 2019$

\section{Background}

Substance use refers to the use of psychoactive substances, including alcohol and illicit drugs. According to Ethiopia Demographic and Health Survey,2016 report, 4\% of men and $<1 \%$ of women smoke cigarettes, 35\% of women and $46 \%$ of men reported drinking alcohol at some point in their lives and $12 \%$ of women and $27 \%$ of men reported having ever chewed khat [1].

The use of substances such as alcohol, khat(Catha edulis; a green leaf chewed for its stimulant effect), and tobacco is becoming common in the universities of Ethiopia. Universities are relatively the place where students easily practice their own choices compared to high schools. The involvement of parents in the academic activities of the students at university is less. Studies show that prevalence of substance use varies across different universities. According to the previous studies, alcohol use prevalence among university students ranges from $11.4 \%$ [2] to $68 \%[3]$. Cigarette smoking prevalence ranges from $10 \%[4]$ to $73 \%[3]$ while khat chewing prevalence ranges from $6.9 \%[5]$ to $35 \%[6]$.

\subsection{Pushing Factors of Substance Use among University Students}

Several pushing factors of substance use among university students can be classified into external and internal factors. External factors include socio-cultural influences and peer pressure. Studies reveal that socio-culture has an impact on students' substance use status. For instance, a qualitative research done by Dázio [7] shows that male university students share the rules of their socio-cultural environment that values the use of alcohol and/or other drugs to cope with stress ensuing from the everyday university life, and to build identity and belong to this social context, reinforcing the influence of the culture. Similarly, a study done in Jimma university shows that social background (whether or not khat grows in the student's home region) has positive significant association with khat use at university[6]. Several studies done on substance use in the universities show that peer pressure is the most frequently reported factor by the students for the initiation of substance use [4,6,8-15]. Study done by Dachew [16] shows that students who had friends who chewed khat were about four times more likely to use khat as compared to those who do not have khat chewer friends.

Regarding to internal factors, different studies have reported that students use substances for enjoyment $[4,11,14,15,17,18,19]$, enhance their academic performance [4,8,11,14,15,17,18-21] and cope with any stress[3,4,7,16,19-22]. It might be due to these internal factors that remarkable proportion of students had started 
using substances after they joined university $[5,15,19,23]$.

\subsection{Impact of substance use}

Use of substance for any reason has multiple consequences including health, social and academic problems. Regarding the health effects of substance use, many researchers find out several health outcomes including psychiatric morbidities [9,14,17,18,24], periodontitis [9,14,25,26], risk behavior for HIV/AIDS [26], problems of blood pressure [26,27], heart rate [27] and digestive system [18,24]. Since substance users exhibit deviant behavior, the society considers them as a threat to the other member of the society [28]. Therefore, substance use impairs occupational and social functioning of the user. Similarly, studies have shown that substance use affects academic performances of the students [8]. Unlike the expectation of substance users, some studies reveal that substance user students' academic performance is lower than that of non-users $[6,28,29]$. This might be because of the high absenteeism rate from class and exam among substance users [30].

Irrespective of all of these evidences against substance use, students in Ethiopia universities use substances especially khat to enhance their academic performance. Therefore, this study was aimed to compare the academic performance of substance user with that of non-substance user students. Independent t-test was performed to test whether substance users' academic performance is better than the non-substance users as they perceived. The finding of this study is useful in planning and developing different strategies to help students quit substance use.

\subsection{Objective of the Study}

The objective of this study was to test whether the academic performance of substance user undergraduate students is different from that of non-substance users.

\section{Methods}

\subsection{Study Design}

In this study, quantitative cross sectional study design was employed to compare academic performance of substance users with academic performance of non-substance users.

\subsection{Study Population}

The study population for this study was all regular undergraduates of health sciences who were graduated at Ambo University in 2017.

\subsection{Sample size}

The study comprises 170 undergraduate students who were recruited in Public health, Nursing, Pharmacy and Midwifery programs run under the college.

\subsection{Data Collection Method}

Since the population size was relatively small $(\mathrm{N}=170)$, census survey was conducted to get a full picture of the target population.

\subsection{Data Collection Instrument}

The data was collected using anonymous self administered questionnaire developed to collect data to achieve the study's objective. The content of the questionnaire includes the socio-demographic characteristics, substance use status and academic performance indicator variables.

\subsection{Study variables}

2.6.1. Dependent variables.

The dependent variable of this study was academic performance measured by:

- UEES: Standardized university entrance examination score out of 700 points the students achieved at grade 12 which was administered by ministry of education and

- CGPA: Cumulative grade point averages out of 4.00 points they achieved at university in the final year. 2.6.2. The independent variable

Independent variables of the study include sex, department, residence, religion and ethnic group and substance use status of the students. In this study, substance use status which refers to whether a student has been using at least one of the substances (alcohol, khat or cigarette) was used as a stratifying factor in comparing academic performance of the students.

\subsection{Statistical Analysis}

\subsubsection{Hypothesis formulation}

Two sided hypothesis was formulated to answer the research question: "is there a significant 
difference in mean CGPA between substance user and non-substance user students?"

$H_{0}$ :Thereis no differencein mean CGPA between the two groups $\left(\mathrm{H}_{0}: \mu_{1}-\mu_{2}=0\right)$

$H_{1}$ : There is a differencein mean CGPA between the two groups $\left(\mathrm{H}_{1}: \mu_{1}-\mu_{2} \neq 0\right)$

\subsubsection{Statistical Test}

Independent samples t-test was employed to compare academic performance of two groups of students based on CGPA they achieved at final year. The students were placed into two distinct groups according to their substance use status.

Important notations used in the hypothesis test were defined as follow:

- $n_{1}$ refers to number of substance user students

- $n_{2}$ refers to number of non - substance user students

- $\mu_{1}$ refers to population mean CGPA of substance user students

- $\mu_{2}$ refers to population mean CGPA of non - substance user students

- $\bar{X}_{1}$ refers to sample mean CGPA of substance user students

- $\bar{X}_{2}$ refers to sample mean CGPA of non - substance user students

- $\mathrm{S}_{1}^{2}$ refers to sample variance CGPA of substance user students

- $\mathbf{S}_{2}^{2}$ refers to sample variance CGPA of non - substance user students

The significance level $(\alpha)$ of the hypothesis test was set to 0.05 .

2.7.3. Test statistic

Under the null hypothesis $\left(H_{0}: \mu_{1}-\mu_{2}=0\right)$ and equal variance assumption, test statistic is given as:

$$
t_{\text {statistic }}=\frac{\bar{X}_{1}-\bar{X}_{2}}{s_{p} \sqrt{\frac{1}{n_{1}}+\frac{1}{n_{2}}}} \sim t\left(n_{\left.n_{1}+n_{2}{ }^{-2}\right)}\right.
$$

Pooled variance is computed as:

$$
S_{p}^{2}=\frac{\left(n_{1}-1\right) S_{1}^{2}+\left(n_{2}-1\right) S_{2}^{2}}{n_{1}+n_{2}-2}
$$

Since the test is two sided, $P$-value is computed as:

$$
P-\text { value }=2 \times P\left(t_{\left(n_{1}{ }^{+} n_{2}-2\right)}>t_{\text {statistic }}\right) ; \text { where } \mathrm{n}_{1}+n_{2}-2 \text { is degrees of freedom }
$$

Then, P-value is compared with the significance level $(\alpha)$ to suggest the observed difference in mean CGPA between the two groups is significant or not.

\subsubsection{Software Used}

Statistical analysis was performed using SPSS version 21. Both descriptive and inferential statistical analyses were performed. Socio-demographic, substance use status and academic performance indicator variables of the study participants were summarized by descriptive statistics. Then, independent samples t-test was done to test the significance of mean difference in UEES and CGPA between substance user and non-substance user students. Pvalue $<0.05$ was considered to be statistically significant.

\section{Results}

This part contains the result of the study and presented thoroughly. The questionnaires were distributed to all of the students consisting 170(125 males and 45 females) undergraduates from the four programs. However, only 133(92 male and 41 female) graduates successfully completed and returned the questionnaires, yielding a response rate of $78.2 \%$. Therefore, data from 133 completed questionnaires were used for the analysis in this study. 


\subsection{Socio-demographic Characteristics of the study participants}

This part contains the result of the study and presented thoroughly. Accordingly, socio-demographic summary, substance use status and hypothesis test results in academic performance comparison among substance user and non-substance user students were presented. The analysis was performed based on data collected from 133 undergraduate graduates. The study participants comprises 40(30.1\%) Nursing, 42(31.6\%), Public health, 20(15.0\%) Pharmacy and 31(23.3\%) Midwifery department graduates. The result shows that, more than half, $72(54.1 \%)$ of them were from rural residence. Concerning their ethnic group, the study participants classified into $89(66.9 \%)$ Oromo, 29(21.8\%) Amhara and 15(11.3\%) Others. Besides, according to their religion, the participants were further classified into 65(48.9\%) Orthodox, 34(25.6\%) Protestant, 29(21.8\%) Islam and 5(3.8\%) others (table 3.1).

Table3.1. Socio-demographic summary of undergraduate graduates of 2017, Ambo University College of Medicine and Health Sciences.

\begin{tabular}{llll}
\hline Characteristics & & Frequency & percentage \\
\hline Sex & Male & 92 & $69.2 \%$ \\
Department & Female & 41 & $30.8 \%$ \\
& Nursing & 40 & $30.1 \%$ \\
& Public Health & 42 & $31.6 \%$ \\
& Pharmacy & 20 & $15.0 \%$ \\
Birth place & Midwifery & 31 & $23.3 \%$ \\
& & 72 & $54.1 \%$ \\
Religion & Rural & 61 & $45.9 \%$ \\
& Urban & 65 & $48.9 \%$ \\
& Orthodox & 34 & $25.6 \%$ \\
& Protestant & 29 & $21.8 \%$ \\
Ethnic group & Islam & 5 & $3.8 \%$ \\
& Others & 89 & $66.9 \%$ \\
& Oromo & 29 & $21.8 \%$ \\
& Amhara & 15 & $11.3 \%$ \\
\hline
\end{tabular}

\subsection{Substance use status of the study participants}

Out of the study participants 60(45.1\%) have used at least one of the substances (alcohol, khat or cigarette). Regarding the prevalence of each substance use, 54(40.6\%) have used alcohol, 20(15.0\%) khat and 4(3.0\%) cigarette (table 3.2).

Table 3.2. Substance use status of undergraduate graduates of 2017, Ambo University College of Medicine and Health Sciences.

\begin{tabular}{lcll}
\hline Substances use & & Frequency & Percentage \\
\hline Substance user (alcohol, khat, cigarette) & 60 & $45.1 \%$ \\
None substance user & & 73 & $54.9 \%$ \\
Alcohol drinking: & Alcohol user & 54 & $40.6 \%$ \\
& Non-alcohol user & 79 & $59.4 \%$ \\
Khate chewing: & Khat user & 20 & $15.0 \%$ \\
& Non-khat user & 113 & $85.0 \%$ \\
Cigarette smoking: & Cigarette user & 4 & $3.0 \%$ \\
& Non-cigarette user & 129 & $97.0 \%$ \\
\hline
\end{tabular}

\subsection{Descriptive summary of the students' academic Performance}

As can be seen from table 3.3, Average university entrance exam score of substance user students was $440.7(\mathrm{SD}=$ 26.2) while it was 436.3 ( $\mathrm{SD}=26.7)$ for non-substance users. Regarding to their academic achievement at university, average cumulative grade point average (CGPA) of substance user students was $3.20(\mathrm{SD}=0.42)$ while it was $3.16(\mathrm{SD}=0.45)$ for non-substance users. 
Table 3.3. Descriptive summary of the students' Academic Performance according to substance use status of undergraduate graduates of 2017, Ambo University College of Medicine and Health Sciences.

\begin{tabular}{|c|c|c|c|c|c|}
\hline $\begin{array}{l}\text { Academic performance } \\
\text { indicator }\end{array}$ & Substance use status & $\mathbf{N}$ & Mean & $\begin{array}{l}\text { Std. } \\
\text { Deviation }\end{array}$ & $\begin{array}{l}\text { Std. Error } \\
\text { Mean }\end{array}$ \\
\hline \multirow{4}{*}{$\begin{array}{l}\text { University entrance } \\
\text { examination score } \\
\text { C GPA }\end{array}$} & Substance user & 60 & 440.7 & 26.2 & 3.39 \\
\hline & Non-substances user & 73 & 436.3 & 26.7 & 3.13 \\
\hline & Substance user & 60 & 3.20 & 0.42 & 0.05 \\
\hline & Non-substances user & 73 & 3.16 & 0.45 & 0.05 \\
\hline
\end{tabular}

\subsection{Academic Performance Hypothesis Test}

As revealed in table 3.4, normality assumption was checked and Shapiro-Wilk test shows that CGPA distribution for substance user and non-substance user population of students are both not normal (For non-substance user: Shapiro-Wilk statistic $=0.961, \mathrm{df}=73, \mathrm{p}$-value $=0.023$; substance user: Shapiro-Wilk statistic $=0.960, \mathrm{df}=60, \mathrm{p}$ value=0.046). Similarly, University entrance exam score distribution for substance user and non-substance user population of students are both not normal (For non-substance user: Shapiro-Wilk statistic $=0.914, \mathrm{df}=73, \mathrm{p}$ value $<0.001$; substance user: Shapiro-Wilk statistic $=0.874, \mathrm{df}=60, \mathrm{p}$-value $<0.001$ ).

Table 3.4. Test of Normality Assumptions for Academic performance indicators distributions

\begin{tabular}{|l|l|r|r|r|r|r|r|}
\hline \multirow{2}{*}{$\begin{array}{l}\text { Academic performance } \\
\text { indicators }\end{array}$} & $\begin{array}{l}\text { Substance } \\
\text { status }\end{array}$ & \multicolumn{2}{|c|}{ Kolmogorov-Smirnov } & \multicolumn{3}{|c|}{ Shapiro-Wilk } \\
\cline { 2 - 7 } & Statistic & \multicolumn{1}{c|}{ df } & \multicolumn{1}{c|}{ Sig. } & Statistic & \multicolumn{1}{c|}{ df } & \multicolumn{1}{c|}{ Sig. } \\
\hline \multirow{2}{*}{ CGPA at final year } & Non-substance users & .072 & 73 & $.200^{*}$ & .961 & 73 & .023 \\
\cline { 2 - 8 } & Substance users & .087 & 60 & $.200^{*}$ & .960 & 60 & .046 \\
\hline \multirow{2}{*}{$\begin{array}{l}\text { University entrance } \\
\text { exam score }\end{array}$} & Non-substance users & .159 & 73 & .000 & .914 & 73 & .000 \\
\cline { 2 - 8 } & Substances users & .149 & 60 & .002 & .874 & 60 & .000 \\
\hline
\end{tabular}

As can be seen from table 3.5, Levene's Test for Equality of Variances shows, variability of university entrance exam score among substance user students was similar with the variability of non-substance users $(F=0.003, p$-value $=0.96)$. Similarly, variability of average cumulative grade point (CGPA) among substance user students was similar with the variability of non-substance users $(\mathrm{F}=0.036, \mathrm{p}$-value $=0.850)$.

As revealed in table 3.5, independent samples t-test results show that there was no significant mean difference in UEES achievement between substance user and non-substance user students (Mean difference $=4.34 ; 95 \% \mathrm{CI}=$ -4.8 to $13.5 ; \mathrm{t}=0.939, \mathrm{df}=131, \mathrm{p}$-value $=0.349$ ). The average cumulative grade point (CGPA) of substance user students was not also statistically significantly different from that of non-substance users (Mean difference $=0.04$; $95 \% \mathrm{CI}=-0.11$ to $0.19 ; \mathrm{t}=0.549, \mathrm{df}=131, \mathrm{p}$-value $=0.584)$.

Table 3.5. Independent t-test of Academic Performance according to substance use status among Ambo University College of Medicine and Health Sciences' students graduated in 2017.

\begin{tabular}{|c|c|c|c|c|c|c|c|c|c|}
\hline \multirow[t]{3}{*}{$\begin{array}{l}\text { Academic performance } \\
\text { indicator }\end{array}$} & \multicolumn{2}{|c|}{$\begin{array}{l}\text { Levene's } \\
\text { Test for } \\
\text { Equality of } \\
\text { Variances }\end{array}$} & \multicolumn{7}{|c|}{ t-test for equality of Means } \\
\hline & \multirow[b]{2}{*}{$\mathrm{F}$} & \multirow[b]{2}{*}{ Sig. } & \multirow[b]{2}{*}{$\mathrm{t}$} & \multirow[b]{2}{*}{$\mathrm{df}$} & \multirow{2}{*}{$\begin{array}{l}\text { Sig.(2- } \\
\text { tailed) }\end{array}$} & \multirow{2}{*}{$\begin{array}{l}\text { Mean } \\
\text { difference }\end{array}$} & \multirow{2}{*}{$\begin{array}{l}\text { Std. Error } \\
\text { Difference }\end{array}$} & \multicolumn{2}{|c|}{$\begin{array}{l}95 \% \text { CI of the } \\
\text { difference }\end{array}$} \\
\hline & & & & & & & & Lower & Upper \\
\hline $\begin{array}{l}\text { UEES(equal variance } \\
\text { assumed) }\end{array}$ & 0.003 & 0.96 & 0.939 & 131 & 0.349 & 4.34 & 4.62 & -4.8 & 13.5 \\
\hline $\begin{array}{l}\text { CGPA (equal variance } \\
\text { assumed) }\end{array}$ & 0.036 & 0.850 & 0.549 & 131 & 0.584 & 0.04 & 0.08 & -0.11 & 0.19 \\
\hline
\end{tabular}

\section{Discussion}

The purpose of this study was to compare academic performance of substance user and non-substance user undergraduate students. The attempt was also made to estimate the proportion of the graduates using alcohol, khat and cigarette. Even though this study addressed all of the 170 undergraduate graduates of 2017 from the four programs run under the college of Medicine and Health Sciences, only 133 of them successfully completed and returned the questionnaire yielding $78.2 \%$ response rate.

Prevalence of at least use of one of the substances: alcohol, khat or cigarette among ambo University undergraduate students is $60(45.1 \%)$. According to the finding of the study, $40.6 \%$ of undergraduates have used alcohol, $15.0 \%$ khat and 3.0\% cigarette. The most commonly used substance among Ambo University students is alcohol while cigarette was rarely used accounting only $3 \%$.

Prevalence of alcohol use in among Ambo university students is higher than that of the other Ethiopia universities students $[2,4,9,13]$. However, there are also other universities whose students' alcohol use prevalence 
is higher than Ambo university's students $[15,19]$. Regarding khat use, prevalence of khat chewing among students of majority of other universities in the country $[4,6,13,14,15,18,19,23]$ is higher than the prevalence of khat chewing among Ambo university students. In contrary, in few universities [5,12,16] prevalence of their students' khat use is less than that of Ambo University students. When cigarette use concerned, Ambo University students rarely use it compared to the research result from the other Ethiopia University [4]. The discrepancies in prevalence of substances might be because of socio-cultural norm differences in the different areas towards substance use. For instance khat use proportion in Ambo University is lower than other universities because of the fact that Ambo University is not located in khat growing area.

Levene's Test of Equality of variances shows that equality of variances assumption was met in both university entrance examination score $(\mathrm{F}=0.003, \mathrm{P}$-value $=0.96)$ and $\mathrm{CGPA}(\mathrm{F}=0.036, \mathrm{P}$-value $=0.850)$ distributions.

However, test of normality suggests that both academic performance indicators (university entrance examination score and CGPA) distributions violet normality assumption. Even though, the distributions of academic performance indicators in each group violet normality assumption, Central Limit Theorem was taken into consideration as the sample size in each group was large enough $(n \geq 30)$. Therefore, independent samples t-test produces valid statistical inferences in this case.

The average university entrance exam score of substance user was $440.7(\mathrm{SD}=26.2)$ compared to 436.3( $\mathrm{SD}=26.7)$ for non-substance user students. Independent t-test result shows that both substance user and nonsubstance user students joined the university with similar level of high school academic performance (Mean difference $=4.34 ; 95 \% \mathrm{CI}:-4.8$ to $13.5 ; \mathrm{t}=0.94, \mathrm{df}=131, \mathrm{p}$-value $=0.35)$. Average cumulative grade point average (CGPA) of substance user graduates was $3.20(\mathrm{SD}=0.42)$ while it was $3.16(\mathrm{SD}=0.45)$ for non-substance users. Similarly, the average cumulative grade point (CGPA) of substance user undergraduates was not statistically significantly different from that of non-substance users (Mean difference $=0.04 ; 95 \% \mathrm{CI}$ : -0.11 to 0.19 ; $\mathrm{t}=0.549, \mathrm{df}=131, \mathrm{p}$-value $=0.584)$. In contrast, the previous studies have reported that substance user students' academic performance was lower than that of the non-substance users $[6,28,29]$. In this study, the hypothesis test result was against substance user students' perception of substance use to enhance academic performance.

\section{Conclusion}

Studies have shown that students use substances for different reasons including: to enhance their academic performance, for stimulant effect, to overcome stress and to be integrated with substance using community (groups). Prevalence of using at least one of the substances: alcohol, khat or cigarette among ambo University undergraduate students was 60(45.1\%). The most commonly used substance was alcohol while cigarette was rarely used accounting only $3 \%$ of the study participants. There was inconsistence prevalence of substance uses among Ethiopia Universities' students. Since substance use is learned behavior, the discrepancies in prevalence of substance use among the students could be due to socio-cultural norm difference towards substance use.

The hypothesis test results show that the substance user and non-user students' academic performance was similar both in university entrance exam score and CGPA. Therefore, substance user students were compromised their health and social functioning for no more better educational attainment than non-substance user students. Thus, this study finding implies that the use of substances to enhance academic performance is wrong perception and harmful practice.

\section{Abbreviations}

AIDS: Acquired immune deficiency syndrome; CGPA: Cumulative grade point average; HIV: Human immune virus; SD: Standard deviation; SPSS: Statistical package for social Sciences; UEES: university entrance examination score.

\section{Declarations}

- $\quad$ Ethics approval and consent to participate

The study was approved by Research and Ethical Review Committee of College of Medicine and Health Sciences, Ambo University. Since the study does not involve activities that affect the participants in any ways, the committee approved verbal informed consent. Accordingly, verbal informed consent was obtained from the study participants.

\section{- Consent to publish}

Not applicable

- Availability of data and materials

Data used for this study is available from the author on reasonable request

- Competing interests

There is no potential conflict of interest to disclose in this study 


\section{- Funding}

There was no financial support received from any institution for this study.

\section{- Authors' Contributions}

Not applicable

\section{Acknowledgments}

I would like to thank all the students who participated in the study.

\section{References}

[1]. Central Statistical Agency, Ethiopia. Demographic and Health Survey,2016. Available from: https://dhsprogram.com/pubs/pdf/FR328/FR328.pdf. [Accessed on 20th, September 2017].

[2]. Mekonen T, Fekadu W, Chane T and Bitew S. Problematic Alcohol Use among University Students. Front. Psychiatry. 2017;8:86. doi: 10.3389/fpsyt.2017.00086.

[3]. Padhy GK, Das S, Sahu T, Parida S. Prevalence and Causes of Substance Abuse Among Undergraduate Medical College Students. Indian Medical Gazette. 2014:276-282.

[4]. Tsegay G, Esmael A. Psychoactive Substances Use (Khat, Alcohol and Tobacco) and Associated Factors among Debre Markos University Students, North-West Ethiopia, 2013. Journal of Defense Management. 2014; 4(1): 1-7. DOI: 10.4172/2167-0374.1000118.

[5]. Sinshaw A, Messele A , Kassa H. Prevalence and Associated Factors of Khat Chewing Among Atse Fasil Campus Students, University of Gondar, North West Ethiopia June 2013. Journal of Psychology \& Clinical Psychiatry. 2014;1(6): 1-8.

[6]. Abafita J, Chala BW, Eba K,Kim KR, Kim CS. Khat use and its impact on academic performance: The case of Jimma University, Ethiopia. Educational Research and Reviews. 2015; 10(15):2084-2095. DOI: 10.5897/ERR2015.2351.

[7]. Dázio EMR, Zago MMF, Fava SMCL. Use of alcohol and other drugs among male university students and its $\begin{array}{lllll}\text { meanings. } & \text { Rev } & \text { Esc }\end{array}$ DOI: http://dx.doi.org/10.1590/S0080-623420160000600011.

[8]. Enyi Uko Jairus et al. Effect of Alcohol Consumption on Students' Academic Performance in Tertiary Institution (A Case Study of College of Education, Oju). Ijsrm.Human. 2017; 6 (2): 66-78.

[9]. Tulu SK, Keskis W. Assessment of Causes, Prevalence and Consequences of Alcohol and Drug Abuse among Mekelle University, College of Social Sciences and Languages, 2nd Year Students. American Journal of Applied Psychology. 2015;3(3): 47-56. doi: 10.12691/ajap-3-3-1.

[10]. Eze CE, Uzoeghe UI. Alcohol Use Among Full-Time Students of the University of Abuja. International Journal of Emergency Mental Health and Human Resilience. 2015;17(1): 283-287.

[11]. Yahya A, Rajeshwar Y, Eticha T, Kahsay G, Ali D, Gebretsadik H et al. Socio-Economic and Health Effects of Khat Chewing in Mekelle, Tigray Region, Ethiopia. Ijppr.Human. 2016; 8 (1): 11-22.

[12]. Admasu E, Tariku B, Andargie G, Hibdye G, Asegidew W. Prevalence, Pattern and Associated Factors of Khat Chewing Among Debre Berhan University Students, Ethiopia. Biol Med (Aligarh). 2018; 10(2):1-8. doi:10.4172/0974-8369.1000431.

[13]. Kassa A, Wakgari N, Taddesse F. Determinants of alcohol use and khat chewing among Hawassa University students, Ethiopia: a cross sectional study. African Health Sciences. 2016; 16(3):822-830. DOI: http://dx.doi.org/10.4314/ahs.v16i3.24.

[14]. Zeleke A, Awoke W, Gebeyehu E, Ambaw F. Khat chewing practice and its perceived health effects among communities of Dera Woreda, Amhara region, Ethiopia. Open Journal of Epidemiology. 2013;3:160-168.

[15]. Mamo DB, Abuhay DA, GelawBK, Tegegne GT. Assessment on the prevalence and contributing factors of social drugs utilization among university of Gondar regular undergraduate students, maraki campus, 2013. International Journal of Pharma Sciences and Research (IJPSR). 2014; 5(8):518-530.

[16]. Dachew BA, Bifftu BB, Tiruneh BT. Khat use and Its Determinants among University students in Northwest Ethiopia: A multivariable analysis. International Journal of Medical Science and Public Health. 2015; 4 (3): 319-323.

[17]. Olujide A, Sussan A, Olufunke C, Frederick A, Muyiwa S. Assessment of Alcohol and Substance Use among Undergraduates in Selected Private Universities in Southwest Nigeria. IOSR Journal Of Humanities And Social Science (IOSR-JHSS). 2015; 20(3):1-7. DOI: 10.9790/0837-20320107.

[18]. Teni FS, Surur AS, Hailemariam A, Aye A, Mitiku G, Gurmu AE, et al. Prevalence, reasons, and perceived effects of Khat chewing among students of a college in Gondar town, Northwestern Ethiopia:A crosssectional study. Ann Med Health Sci Res. 2015;5:454-60. DOI: 10.4103/2141-9248.177992.

[19]. Tesfaye G, Derese A, Hambisa MT. Substance Use and Associated Factors among University Students in Ethiopia: A Cross-Sectional Study. Hindawi Publishing Corporation Journal of Addiction.2014: 1-8. DOI: http://dx.doi.org/10.1155/2014/969837. 
[20]. Meressa K, Mossie A, Gelaw Y. Effect of substance use on academic achievement of health officer and medical students of Jimma University, Southwest Ethiopia. Ethiop J. Health Sci . 2009; 19(3):155-163.

[21]. Gebiresilus AG, Gebresilus BG, Yizengaw SS, Sewasew DT, Mengesha TZ. KHAT USE PREVALENCE, CAUSES AND ITS EFFECT ON MENTAL HEALTH, BAHIR-DAR, NORTH WEST ETHIOPIA. European Scientific Journal. 2014; 10(23):234-253.

[22]. Desta E, Soboka M, Workneh D, Gashaw BT. The Prevalence of Substance Use and Associated Factors Among Medical Interns of Jimma University, South West Ethiopia. Journal of Substance Abuse \& Alcoholism. 2018; 6(1):1-8.

[23]. Abdeta T, Tolessa D, Adorjan K , Abera M. Prevalence, withdrawal symptoms and associated factors of khat chewing among students at Jimma University in Ethiopia. BMC Psychiatry. 2017; 17(142):1-11.

[24]. Uchendu UI, Ukonu OI. Effect of Substance Use on Academic Performance among Undergraduate Students In The University Of Abuja, Nigeria. Journal of Research in Humanities and Social Science. 2016; 4(3): 6271.

[25]. BASKER VG. A REVIEW ON HAZARDS OF KHAT CHEWING. International Journal of Pharmacy and Pharmaceutical Sciences.2013;5(3):74-77.

[26]. Kalakonda B, Al-Maweri SA, Al-Shamiri HM, Ijaz A, Gamal S, Dhaifullah E. Is Khat (Catha edulis) chewing a risk factor for periodontal diseases? A systematic review. J Clin Exp Dent. 2017;9(10):e1264-70.

[27]. Chong ZX, Alshagga M, Saed KA, Kassim S. IMPACT OF KHAT (CATHA EDULIS) CHEWING/USE ON HEART RATE AND BLOOD PRESSURE: A CRITICAL REVIEW. Malaysian Journal of Public Health Medicine. 2017;17(3): 76-85.

[28]. Kavutha MJ. Influence of Drug Use on Academic Performance among Secondary School Students in Matinyani District, Kenya. International Journal of Scientific and Research Publications. 2015; 5(11): 726-731.

[29]. AKANBI MI, Augustina G, Theophilus AB, Muritala M, Ajiboye AS. Impact of Substance Abuse on Academic Performance among Adolescent Students of Colleges of Education in Kwara State, Nigeria. Journal of Education and Practice. 2015; 6(28):108-112.

[30]. WELCOME MO, MASTORAKIS NE, RAZVODOVSKY YE, PEREVERZEVA EV, PEREVERZEV V. Relationship between Alcohol Consumption and Academic Success of Medical Students in Minsk, Belarus. Advances in Environmental Science and Energy Planning. 235-244. 